\title{
DISAGREEMENT, UNILATERAL JUDGMENT, AND KANT'S ARGUMENT FOR RULE BY LAW
}

\author{
Daniel Koltonski
}

$\rrbracket$

T IS A COMMON THOUght that authoritative law is necessary because we disagree about justice. This idea often rests on law's purported instrumental value, on its ability to get us, imperfect and biased agents, closest to a just society: we do best, from the perspective of justice independently defined, by having clear legal rules to follow and rights to respect. In The Doctrine of Right, Kant rejects such an instrumental conception of law and instead defends the more controversial claim that, absent authoritative law, there will often be no answer to be had about what justice (or, for Kant, right) requires of us in our interactions with one another. On this view, in a situation without authoritative law - in a state of nature - a person is unable coherently to pursue the aim of acting rightly. Authoritative law is required for Kant, then, not because a person, in obeying the law, is thereby more likely to do what right demands; rather, it is required because without it, there will often be no sense to be made of this question of what right demands.

The problem with the state of nature, according to Kant, is that it is "a state devoid of justice ..., in which when rights are in dispute ... there would be no judge competent to render a verdict having rightful force." ${ }^{1}$ Kant argues:

However [good and right-loving] human beings might be, it still lies a priori in the rational idea of such a condition (one that is not rightful) that before a public lawful condition is established, individual human beings ... can never be secure against violence from one another, since each has its own right to do what seems right and good to it and not to be dependent upon another's opinion about this. ${ }^{2}$

1 Kant, The Metaphysics of Morals, 6:312. All citations to Kant are to the Akademie numbers listed in the margins of most editions; unless otherwise stated, all English translations of Kant's Doctrine of Right are from Practical Philosophy, translated and edited by Mary Gregor.

2 Kant, The Metaphysics of Morals, 6:312. Translation in brackets from Ripstein, Force and Freedom, 146. 
He continues:

So, unless it wants to renounce any concepts of right, the first thing it has to resolve upon is the principle that it must leave the state of nature, in which each follows its own judgment, unite itself with all others (with which it cannot avoid interacting) $\ldots$ and so enter into a condition in which what is to be recognized as belonging to it is determined by law and is allotted to it by adequate power ... that is, it ought above all else to enter a civil condition. ${ }^{3}$

As the literature on this argument makes clear, the basic difficulty with the state of nature is not that persons, even entirely "good and right-loving" ones, cannot be secure from violence - though this is an important consequence-but rather that they cannot respect one another's equal freedom when they act on their own judgments of right in circumstances of disagreement among them. The idea here is that when someone interacts with another according to her own judgment of right, she implicitly claims that her judgment governs this interactionit binds them both - while his conflicting judgment does not. And he implicitly claims something similar when he interacts with her according to his judgment of right. They each implicitly claim a power to bind the other that they deny the other has to bind them, a claim inconsistent with "innate equality," itself an aspect of our freedom: "independence from being bound by others to more than one can in turn bind them." Kantians call this "the problem of unilateralism": in the state of nature, acting on your own judgment of right contains within it the claim that your will is unilaterally lawgiving for those with whom you interact. ${ }^{5}$

As one quite natural understanding of this problem of unilateralism has it, you judge that $x$, she judges that not- $x$, and for you to take your judgment to be what governs this interaction is for you to treat as special the fact that you judge that $x$. You treat your judgment of right as having authority over the interaction, and so also over her, simply because the judgment is yours; in so doing, you deny that same authority to her differing judgment in violation of innate equality. This understanding of the problem, however, faces the objection that it misunderstands the reason you act on when you act on your own judgment in

3 Kant, The Metaphysics of Morals, 6:312.

4 Kant, The Metaphysics of Morals, 6:237.

5 Persons' lack of security from violence in the state of nature is thus the result of the absence of a mechanism for resolving for them their inevitable disagreements about right. When such disagreements arise, each will act on their own judgment of the matter, standing up to others in defense of what they take right to be. Everyone will thus be subject to coercive threat-as doing only what you judge consistent with right will be no protection from others who may disagree - and, in that way, no one will be secure from violence. 
circumstances of disagreement. Your judgment governs this interaction, on your view, not because it is yours but rather because it is correct. Or, as David Enoch puts it, "your reason for action is not that you believe so-and-so (where others believe otherwise), but rather that so-and-so." ${ }^{6}$ Here, then, "it's just not about you at all. So, there is no sense in which you're giving extra weight to your beliefs over others-you're giving no weight to your beliefs here." ${ }^{7}$ And so, in acting on your judgment in the state of nature, imposing it on others who disagree, you are not thereby claiming a special power to bind them in violation of innate equality. Call this Enoch's Objection. ${ }^{8}$

My aim here is to defend the Kantian account of the problem of unilateralism against Enoch's Objection and, in so doing, to illuminate the feature of the Kantian conception of right that accounts for why, however "good and right-loving" they might be, persons in a state of nature about right are unable coherently to pursue the aim of acting rightly. Notably, this problem of unilateralism is not unique to the domain of right but rather arises more generally, and less controversially, in state-of-nature versions of other rule-governed interactions. The case against Enoch's Objection thus begins by arguing that when it comes to state-of-nature versions of these other interactions, the objection fails. The focus here will be on certain multiplayer games and, in particular, on those games whose rules give players the freedom to decide for themselves what moves to play on a field of play that they share, with chess and baseball as paradigm cases. In these games, players have a right of self-governance: the right to choose for themselves which move, among the legitimate moves open to them, to play. The difficulty is that some of these games would be unplayable were the game's rules to give players a second right of self-governance: the right to act on their own judgments of which moves, according to the game's conduct rules, are legitimate in the first place. Giving players this second right would be to put them in a state of nature with one another about the game's conduct rules, and so the claim is that some of these games are unplayable as state-of-nature games.

6 Enoch, "Not Just a Truthometer," 982. The notion of a reason here is "the agent's reason," or "the consideration in light of which the agent acted, the feature of the situation that made the relevant action one the agent thought worth performing." See Enoch, Taking Morality Seriously, 221-23.

7 Enoch, “Against Public Reason,” 131. As Enoch notes, Joseph Raz makes this same general point in his "Disagreement in Politics."

8 Enoch offers this objection specifically against what he calls "public-reason accounts." His specific targets are John Rawls's Political Liberalism (Enoch, "Against Public Reason,” 13034) and Gerald Gaus's The Order of Public Reason (Enoch, "The Disorder of Public Reason," 156-60). But, as Thomas Sinclair notes, this objection can also be directed at Kant's problem of unilateralism. See Sinclair, “The Power of Public Positions," 31. 
The basic issue with state-of-nature versions of these games is that players can responsibly disagree about what the conduct rules say about the legitimacy of some move. When such disagreement is possible, there will not be one status for the move-either legitimate or not - that they all are accountable for recognizing as the status it has within their game. The result is that the status of this move in their game, and so the status that governs (or has authority over) their individual game play, is indeterminate. (While what the conduct rules say about the move may be determinate, it may not be accessible to these players.) When a player nevertheless exercises her rights of self-governance in this context of responsible disagreement, playing a move she responsibly judges that the conduct rules say is legitimate, she cannot help but implicitly claim that her judgment has decided for their game the move's status within it. She thus claims for herself and her judgment unilateral authority over the game and so over her fellow players - authority she denies to them and their responsible judgments. Her judgment, she claims, resolves the indeterminacy by making the move legitimate in their game. Directed at state-of-nature versions of these games, Enoch's Objection thus fails, for this player is claiming a special power to bind the others in violation of innate equality: in exercising her second right to self-governance in this state-of-nature game, she implicitly denies that her fellows have that same second right. The result is that she is unable to exercise both rights responsibly in a state-of-nature game while understanding it as such - that is, as a game in which everyone, and not just she, has both rights.

After showing that Enoch's Objection fails when applied to state-of-nature versions of these games, I argue that on a Kantian conception of right, the rules of right are relevantly analogous to the rules of these games. It is as if the rules of right place us, along with those with whom we "cannot avoid interacting," into a multiplayer "game" of equal freedom, one whose players, even when idealized as entirely good and right-loving, can responsibly disagree about which "moves" the conduct rules of right declare to be legitimate or not. As a result, Enoch's Objection similarly fails when it comes to a state of nature about right (or when it comes to a state-of-nature "game" of equal freedom). The Kantian account of the problem of unilateralism in a state of nature about right does not make the mistake that the objection claims.

\section{THE INDETERMINACY-OF-RIGHT RESPONSE}

One of Kant's central claims is that right is, in some important sense, indeterminate. ${ }^{9}$ We might try to avoid Enoch's Objection, then, by understanding the

9 See, for instance, Kant, The Metaphysics of Morals, 6:266. 
disagreements about right at issue as instead disputes about how to resolve some indeterminacy of right itself. This indeterminacy claim would give us a version of the problem of unilateralism: by acting on my own judgment when right itself is indeterminate, I am thereby claiming the power to make my answer about right the answer for all of us, a claim of unilateral authority incompatible with innate equality. Recent defenders of the Kantian view have either offered this indeterminacy response or presented an account of the indeterminacy of right that makes such a response possible. Thomas Sinclair, for instance, does the former and Arthur Ripstein, the latter.

For Ripstein, the problem lies in the application of concepts of right: "The application of concepts to particulars is always potentially indeterminate, and so requires judgment, as a result of which the classification of particulars is always, at least in principle, indeterminate. ${ }^{10}$ This indeterminacy is a source of disagreement about right:

There are some cases in which concepts of right completely determine the outcome of a dispute.... In other cases, however, even if it is agreed that concepts of right apply, there can be a dispute about how they apply to particular cases.... Although their internal structure requires a single answer, neither the normative concepts nor the relevant facts nor any combination of them guarantees agreement. ${ }^{11}$

These disagreements are a problem, according to Ripstein, because no one need accept another's answer:

If I believe in good faith that the boundary between our property is in one place, and you, equally in good faith, believe that it is somewhere else, neither of us has any obligation of right to yield to the other.... More generally, neither of us needs to give in to the unilateral judgment of the other as to how to classify particulars. ${ }^{12}$

Thomas Sinclair understands disagreement about right similarly, as having its source in the "inevitable indeterminacy in the application of any general principle [including principles of right] to concrete particulars." ${ }^{13}$ For example:

You and I might agree on the authoritativeness of a law that says clamshells on the beach are mine and clamshells in the sea are yours, and yet 
disagree about this clamshell, which is being moved back and forth by waves on the beach.... If my claim were authoritative, then you (and everyone else) would be subject to constraints privileging my judgment, but I would not be subject to constraints privileging yours. ${ }^{14}$

Both accounts thus hold that were I to regard my judgment as resolving the indeterminacy of right at issue, I would be treating the fact that it is my judgment as special, as what gives it the requisite authority.

One might reasonably wonder whether this indeterminacy response succeeds. In Ripstein's example, the judgments we each make concern where the boundary lies: I believe it is here; you believe it is there. It would seem, then, that I believe that I am correct and you are mistaken, while you believe the opposite. But if so, we are both thus presuming about this question of the boundary that there is a determinate answer, one that we each think we have gotten right. Ripstein's account thus seems to face something like a dilemma. If there is no such answer-if, as Ripstein argues, right itself is indeterminate here-then it would be a mistake to exercise judgment such that one arrives at, as Ripstein's account has it, a good-faith belief about where the boundary lies. Or if this is not a mistake-if it is somehow appropriate to form good-faith beliefs about where the boundary lies in a case like this - then this response does not avoid Enoch's Objection, for it will still be that when I act on my judgment in a case of disagreement, thereby imposing it on you, my reason is of the form "that $x$ " "that the boundary is here" or "that the boundary is there") not "that I judge that $x$ " or "that I believe that $x$." Granted, if right is indeterminate in these cases, then I will in fact be imposing my answer by acting on my judgment. But I will not thereby be implicitly claiming the unilateral power to make right determinate, for the way I approach the question of right at issue-as one I aim to make the correct judgment about—rules out this implicit claim.

The indeterminacy-of-right response may be able to counter this objection. It is not clear, for instance, whether Sinclair's version of the response is in fact vulnerable to the objection. That will depend, I think, on whether there is available a plausible account of judgment such that my judgment that I own the clamshell does not bring with it a claim of correctness. If there is not, then the authority of my judgment will not, on my view, come from me but from the rules themselves, and Enoch's Objection will still apply. Regardless, a response to Enoch's Objection that depends on the claim that right itself is often indeterminate seems of limited use dialectically, for many of those who reject the Kantian account of the problem of unilateralism for the reasons articulated by Enoch's Objection 
will likely also reject this claim that right itself is often indeterminate. ${ }^{15}$ What we require, it seems to me, is a different response to Enoch's Objection, one that neither relies on nor denies this claim that right itself is often indeterminate, but instead remains neutral with regard to it. Such a response is what I develop in what follows. (This response still holds that there is an important sense in which right is indeterminate, just not in the way that Ripstein and Sinclair claim.)

\section{DISAGREEMENT AND GAMES}

The defense of this different response to Enoch's Objection is somewhat indirect. The argument is first that the Kantian problem of unilateralism is not specific to a state of nature about right but instead arises more generally, and less controversially, in state-of-nature versions of other rule-governed interactions. After showing, in this section, that when it comes to state-of-nature versions of these other interactions, Enoch's Objection fails, I then proceed, in the next section, to show that on a Kantian conception of right, the rules of right are relevantly analogous to the rules of these other interactions. And because Enoch's Objection fails when it comes to state-of-nature versions of these other interactions, it similarly fails when it comes to a state of nature about right. The Kantian account of the problem of unilateralism in a state of nature about right thus does not make the mistake that Enoch's Objection claims.

The focus in this section will be on certain multiplayer games, with chess and baseball as paradigm cases. In the games at issue, players share a field of play, and when it is a player's turn, there are normally multiple moves among which she may choose according to her own view of her ends within the game and how to pursue them. (Winning the game may not be a player's only or even primary end. Indeed, as it is not an obligatory end, it may not be one of her ends at all.) The rules of these games thus give players a right to self-governance:

Right to Self-Governance 1 (RSG1): The right to act within the game according to one's own judgments (rather than deferring to some other's judgments) of which moves, among the legitimate ones, to play.

This section argues that these games must also be structured such that players stand in relationships of accountability with one another about the rules.

For a subset of these games, however, players will not stand in such relation-

15 And this includes Enoch: "Indeterminacy can perhaps play some role in accounting for moral disagreement, but not the key role some thinkers attribute to it" (Taking Morality Seriously, 192n20). 
ships of accountability if the game also gives them a second right to self-governance:

Right to Self-Governance 2 (RSG2): The right to act within the game according to one's own judgments (rather than deferring to some other's judgments) of which moves, according to the game's conduct rules, are legitimate in the first place.

Why is this? The possibility of a certain kind of disagreement about how the conduct rules apply and so about which moves are legitimate-responsible disagreement between players-makes these relationships of accountability impossible when players have not only the first but also the second right to self-governance. Baseball is one such game.

What these games require, then, is some authoritative mechanism that resolves these responsible disagreements such that within the game, moves have one status (i.e., either legitimate or not) that players are to recognize as governing all players, as this will make relationships of accountability between them possible. That the game requires such a mechanism, and so cannot be played as a state-of-nature game, is what would give rise to the problem of unilateralism were players nevertheless to attempt it as a state-of-nature game: when one player exercises her RSG2 and so acts in the game according to her own responsible judgment of the legitimacy of some move, a judgment with which other players might responsibly disagree, she cannot help but implicitly claim, in this instance, to be the authoritative mechanism, required by the game, that decides the legitimacy of moves. This is a claim of unilateral authority over the game and so over her fellow players.

\subsection{Freedom and Accountability within Certain Multiplayer Games}

A player's exercise of the first right of self-governance (RSG1) is, of course, still governed by the game's rules. When pursuing her ends within the game, she may do so only within the bounds set by those rules: for any turn $t$ in the game, she may choose only among those moves that are legitimate at $t$. In this way, her RSG1 is both the right within the game to pursue her ends in her own way and the responsibility for doing so only within whatever bounds the rules, at any $t$, give to that right. We can understand these bounds as the state of play within the game. The state of play at some $t$ is, roughly, where things stand in the game at $t$ - which moves at $t$ are legitimate (or not) and for whom-and it is the product not only of the rules themselves but also of what has happened in the game up to $t$, the legitimate moves that have already been played and, as a result, shape the field of play at $t$. In this way, the state of play at any $t$ in the game is normative, for it tells 
players what at $t$ they are and are not permitted to do next. To say that a player's game play is governed by the rules, and so that she is responsible for abiding by those rules, is thus to say that when pursuing her ends in her own way within the game, she is responsible for doing so using only those moves the current state of play has as legitimate for her.

Because the state of play at any $t$ is, in part, the product of whatever has happened in the game up to $t$, a player's choice of moves, in a game where players share a field of play, is not merely a choice of how to pursue her ends but also a choice of the state of play that will result in that because it will partly determine which moves are subsequently legitimate (or not) for other players on the field of play. There is thus a sort of interdependence between players' freedom within a game in which they share a field of play-a player's pursuit of her ends within the game shapes the bounds the rules subsequently give to her fellows' space for their pursuit of their ends, and vice versa - and so the players are in this way governed together by the rules. One result is that a player's RSG1 contains, as it were, an additional right:

Right to a Legitimate Field of Play: The right that, at any turn $t$, the moves that are legitimate for one to play are indeed playable on the field of play.

Put another way, a player has the right that her fellow players, in their turns shaping the field of play for her, play only moves that the state of play has as legitimate for them. This right to a legitimate field of play, as part of a player's RSG1, thus correlates with her fellow players' responsibility (or duty), as part of their RSG1, to choose only among legitimate moves. The result is not only that players are responsible for choosing only among moves that are legitimate for them but also that they are accountable to one another for doing so: other players have the standing to demand, as something owed to them, that one fulfill this responsibility. And so, because they are governed together by the rules in this way, players stand in relationships of accountability with one another about their exercise of their RSG1. Or at least this is what a game structured in this way, with players each having (and exercising) the RSG1 on a field of play that they share, commits itself to.

But if players are to stand in these relationships of accountability, the game must be structured so as to make such relationships possible. And they will be possible between players, it seems to me, only so long as the state of play at any $t$ is accessible to them. By "accessible" I mean that, barring special (and unfavorable) circumstances, it is the case that players exercising judgment responsibly are able to identify the state of play as such. The basic idea is that a game that gives players the RSG1, if it is to be playable, must also see to it that at least when 
players exercise judgment responsibly in whatever the game presupposes as "ordinary" (or "normal" or "standard") circumstances of game play, these players can fulfill the responsibility contained within their RSG1, one they owe to each other, of playing only legitimate moves. (Special, and unfavorable, circumstances can thus excuse a player's failure to fulfill this responsibility. $)^{16}$

Why is it that players can be accountable to one another in the way these games require only if they themselves can identify the state of play within the game, whatever it is, as such? It is because the claims the game licenses players to make of each other within the game must be compatible with the others' exercise of their RSG1. Suppose one player makes a demand of another about some attempted move: "But you can't do that!" If her demand of him is to be compatible with his RSG1, it cannot be a demand that he defer to her judgment that his move is illegitimate; it must instead be a demand that he recognize its illegitimacy himself, and as such, it presupposes that he can do so, at least in ordinary circumstances, by exercising judgment responsibly himself. ${ }^{17}$ Thus, if she is to be able to make such demands of him, ones her RSG1 entitles her to make, it must be the case that the illegitimacy of his move is accessible not only to her but also to him. The result is thus that players will stand in relationships of accountability with one another only if, for any move played, its status as legitimate or not in the state of play is something that, provided they exercise judgment responsibly, players are able to identify themselves. All of this follows from the game giving players each an RSG1 that they are to exercise on a field of play they share.

\subsection{The Case of Chess}

We can see this at work in a game of chess. In chess, each player has this RSG1: during her turn, she may choose for herself which move, among the legitimate moves, to play in pursuit of her ends. (A player's primary end, of course, may be to win. Even so, she may have several different strategies to choose among, or she may wish to win but, for whatever reason, not too quickly. Or, as winning is not an obligatory end, her end may be something else: to let her opponent win, to

16 In what follows, I do not explicitly include this proviso about valid excuses, but solely for convenience; its presence should be understood as implied throughout.

17 This claim about accountability in these games is related to a claim Stephen Darwall makes about moral obligation and accountability:

If ... you address a putatively authoritative demand to someone to get off your foot and hold him answerable for doing so, you do assume, do you not, that this is something he should be able to see for himself, or at least to appreciate when it is pointed out to him? After all, how can you hold him responsible for doing something for reasons he cannot himself appreciate even when they are pointed out to him? ("Law and the Second-Person Standpoint," 174) 
practice a new and complicated strategy of play, to help her opponent practice it, etc.) Once one player exercises her RSG1, her choice of moves is incorporated into the resulting state of play, and straightforwardly so: her move changes the field of play - the arrangement, and perhaps number, of pieces on the boardand in so doing, it partly determines the moves that are now open (or not) to her opponent for his pursuit of his ends. ${ }^{18}$ Her exercise of her RSG1 thus shapes the bounds the rules impose on his exercise of his RSG1 (and vice versa) — the rules govern them together-and so the game has it that they are accountable to one another for choosing only among the moves the state of play has as legitimate for them. ("You can't take my queen like that! This pawn is in the way.")

In fact, the rules of chess give players not just the first but also the second right of self-governance (RSG2): they may act within the game according to their own judgments of which moves, according to the game's conduct rules, are legitimate in the first place. Chess is thus structured so that players are entirely self-governing. Or, to put it another way, chess puts its players in a Kantian state of nature with one another about its conduct rules: "each has [their] own right to do what seems right and good" to them within the game rather than defer to another.

That chess puts players in a state of nature about its conduct rules does not, however, lead to the problem of unilateralism Kant claims to find in a state of nature about right. It is important to be precise about why. When players exercise their RSG2, the judgments they act on are their judgments of what the conduct rules say the state of play is. This means that by giving players this RSG2, the game defines the state of play at any $t$ as simply what the conduct rules say that it is at that $t$. But what the rules say the state of play is can fulfill the role of the state of play in the game only if what they say is accessible to players - that is, only if, barring special (and unfavorable) circumstances, responsibly exercising this RSG2 will lead them to the correct answer as to what the conduct rules say the state of play is. Otherwise, players will not be accountable to one another for choosing only among the moves the state of play has as legitimate. And in chess the conduct rules are indeed such that what they say about the legitimacy of any move, whether actual or possible, is accessible to players. What is presupposed by a demand addressed by one player to another (that the other player is able, via her own judgments of what the conduct rules say, to recognize the authority of the one's claim about the legitimacy of some move) obtains in a game of chess. The one player is able to make this demand of the other, as it were, on behalf of opponent might be precisely why she chooses the move she does. 
the rules governing them both, and so its authority comes not from the one but from the rules.

In chess, then, players can have (and exercise) both rights of self-governance, and yet when they contemplate their next move or evaluate the legitimacy of their opponent's move, they are able to do so from a view of what the rules say the state of play is that they both are accountable for identifying as correct and so as the state of play in their game. That chess has its players in a state of nature about the conduct rules - their individual game play entirely unregulated by any external authority (such as a referee or an umpire)—does not undermine the maintenance throughout the game of an accessible state of play. The result is that chess players can be entirely self-governing and yet stand in a relationship of accountability with one another.

\subsection{The Case of Baseball, and Enoch's Objection}

But some such games are impossible to play when players have (and exercise) both rights of self-governance. Baseball is one such game. Why might this be? Recall that a game structured so that players have both the RSG1 and the RSG2 is one that has the state of play at any $t$ as simply what the conduct rules say it is at that $t$. For such a game to be playable, then, it must be that what those rules say the state of play is at any $t$ is accessible to players. And this is not the case in baseball, for, unlike in chess, two players each deliberating entirely responsibly in normal circumstances can disagree about how the conduct rules apply to some move played and so about what those rules say the resulting state of play is. Because what the conduct rules say the state of play is at that $t$ is not accessible to the players, there is not one view of the state of play that they all are accountable for recognizing as the state of play in their game. We can thus understand the problem a state of nature poses here for a game of baseball as one of indeterminacy: when disagreement of this sort is possible, what the conduct rules say the state of play is cannot be the state of play in their game-it is unable to fulfill that role-and, as a result, the state of play is indeterminate. (This will be the case even if what the conduct rules say is not itself indeterminate, for what they say can be determinate and yet not accessible to players.)

Alternatively, we can understand the problem the state of nature poses as one of unilateralism: possible disagreement of this sort makes it the case that when one player plays a move that she responsibly judges the conduct rules say is legitimate, she thereby implicitly claims that her judgment of what those rules say about the state of play resolves the indeterminacy and, in that way, decides the state of play in their game. She thus claims for herself and her judgment authority over the game and so over her fellow players, authority she necessarily denies 
to them and their conflicting responsible judgments of what those rules say. As Enoch's Objection is directed at the problem of unilateralism, we will consider it in detail.

Consider a pitch in a state-of-nature baseball game in which Astrid and Bashir are opponents. Exercising judgment responsibly in normal circumstances, Astrid judges the pitch to be a ball while Bashir judges it a strike, and Bashir proceeds to act on his judgment. (Suppose that as a strike, but not as a ball, the pitch ends the inning.) A Kantian might say that in acting here, Bashir is claiming unilateral authority over the status of the pitch in the state of play and so over Astrid as a fellow player. And Enoch might respond that Bashir is not claiming unilateral authority over the pitch's status, for he is acting on his judgment that the pitch is a strike not because it is his but because it is, as he thinks, correct.

Implicit in Bashir's action is not merely "The conduct rules say that the pitch is a strike." Bashir is making a claim within the game of a fellow player-we can imagine Bashir saying to Astrid, "It's a strike!"- and so it is an implicit demand he addresses to Astrid as someone accountable to her fellow players for acting from the state of play. Now, Enoch might argue that it is no problem for his view that Bashir, in acting on his judgment in their game, thereby claims authority for the demand of Astrid implicit in his action, for it has this authority within the game and so over Astrid, on Bashir's view, not because it is his but because it is the correct application of the conduct rules to the pitch. Bashir can thus regard himself as making this demand on behalf of the conduct rules, and so the authority he is claiming for it, on his view, will come not from him but from the rules themselves. As we do not yet have a claim of unilateral authority by Bashir over Astrid, Enoch's Objection seems to stand.

Bashir's view that he is making this demand on behalf of the conduct rules, with its authority over Astrid thus coming not from him but from the rules, presupposes not merely that the rules do, in fact, count the pitch as a strike but also that Astrid is accountable for recognizing that fact and so for identifying "The pitch is a strike!" as part of the state of play. But, as we have established, Astrid is not accountable for identifying this as part of the state of play unless it is accessible to her; and it may not be accessible to her, for it may be that from where she stands in the game, entirely responsible deliberation about what the conduct rules say about the pitch cannot but lead her to the judgment that the pitch is a ball, not a strike. When this is the case and so responsible disagreement about the pitch is possible, the presupposition is false-Astrid is not accountable for recognizing "The pitch is a strike!" as part of the state of play. Thus, Bashir's view that he is making this demand on behalf of the conduct rules, with its authority 
over Astrid thus coming from them, is undermined. (And, again, this will be the case even if the conduct rules do in fact say that the pitch is a strike.)

Now, as this dispute about the pitch's status is one within their game, Astrid and Bashir cannot simply agree to disagree about its status while continuing their game, for the game requires that the pitch have one status in the state of play-either a strike or a ball - that is authoritative for them both. This is why any act of playing the game contains an implicit demand addressed to other players: it makes a claim about the state of play governing them all. By playing their game according to his own judgment that the conduct rules declare the pitch a strike-and thus implicitly claiming that it is a strike in the state of play-Bashir cannot help but address such a demand to Astrid, and so he addresses it whether or not this presupposition obtains (that is, whether or not Astrid is accountable for recognizing "The pitch is a strike!" as what the conduct rules say the state of play is). In acting here, then, Bashir commits himself to the view that there is an available basis for his demand's authority over Astrid that is not the authority of those rules themselves.

What might this basis be? Notice that because this presupposition is false, Bashir cannot say that Astrid would be accountable for recognizing, as part of the state of play, that the pitch is a strike even if he had not yet acted on the relevant judgment and, in so doing, addressed it to her as a demand. But in acting on that judgment and so addressing it to her as a demand, Bashir is thereby claiming authority for it. It seems, then, that Bashir commits himself to the view that it was by his acting on the judgment—and, in doing so, addressing it to her as a demand - that Astrid came to be accountable for abiding by it. Thus, by playing their game according to his own responsible judgments of the conduct rules, even when those judgments admit of responsible disagreement, Bashir commits himself to the view that his judgments decide the state of play-and so that they have authority over Astrid—not because these judgments are correct (although they might be) but because he has acted on them in their game. Bashir thus cannot help but claim unilateral authority over those parts of the state of play at issue.

Where Enoch's Objection goes awry is that Bashir's demands cannot have the authority he claims for them simply because the judgments are, as he thinks, correct applications of the conduct rules, and this is because in baseball (unlike in chess) it may not be that other players are accountable for recognizing the judgments as correct. In playing the game according to his own responsible judgments, what Bashir cannot help but claim is that the demands he implicitly addresses to other players have authority over them because he thinks the judgments his demands contain about how the conduct rules apply are correct. Thus, 
what Bashir demands of Astrid is that she regard his judgment as deciding for their game the status of the pitch in the state of play simply because it is his. And were Astrid to act on her different judgment that the pitch is a ball, she would thereby be making a similar demand of Bashir.

\subsection{Indeterminacy and Unilateralism in the State of Nature}

The problem of unilateralism reveals that there is something incoherent about the very idea of a state-of-nature baseball game. By exercising his right to act on his own responsible judgments of how the conduct rules apply (his RSG2), even when those judgments admit of responsible disagreement, Bashir thereby denies that other players like Astrid have a similar RSG2, for he cannot help but claim unilateral authority within the game for those judgments. In this way, Bashir cannot play in a state-of-nature baseball game while understanding it as a state-of-nature game. And he cannot because, unlike a state-of-nature game of chess (or, simply, a game of chess), a state-of-nature game of baseball is unplayable. The problem of indeterminacy explains why. In normal circumstances, two players can responsibly disagree about what the conduct rules say about a pitch—is it a strike or a ball? — and, as a result, they will be unable to play from a view of what those rules say that they all are accountable for identifying as correct and so as part of the state of play. Consequently, the status of the pitch in their game will be indeterminate, and because the pitch's status is indeterminate and the pitch ends the inning only if it is a strike, whether the inning has ended will also be indeterminate. Unless the game is restructured so that the pitch is given one accessible status in the state of play, thereby resolving the indeterminacy, they will be unable to continue the game.

What Astrid and Bashir's baseball game requires, then, is that it replace a situation where the players all have this RSG2 with some mechanism for the authoritative resolution of disputes arising from players' disagreement about what the conduct rules say. Astrid and Bashir need not think that, as a judgment of what those rules say, this mechanism's resolution of their dispute about the pitch is correct; they need only recognize it as authoritatively settling what the pitch counts as in the resulting state of play. What their game requires, then, is a mechanism that they are to recognize as authoritative for their game even as their disagreements about the correct application of the conduct rules in their game might remain. This mechanism may be formal (e.g., an umpire or one player possessing unilateral authority) or informal (e.g., case-by-case negotiations, as in a casual game). But there must be some such mechanism if they are to be able to play a game of baseball together.

In a baseball game with an umpire, anyone - a spectator, a coach, a player- 
might judge that a pitch satisfies the criteria for a strike, but only the umpire can give that pitch the status of a strike within the resulting state of play. Thus, if a player declares "It's a strike!" she is merely doing the former, judging the pitch to be what we might call a strike ${ }_{1}$, while if the umpire declares "Strike!" he is doing the latter, making the pitch a strike ${ }_{2}$. In making the pitch a strike $e_{2}$, the umpire's judgment settles the state of play for the players such that the pitch counts as a strike in their game. The umpire's judgment is authoritative-it governs their subsequent game play-while a player's judgment that the pitch is a ball $l_{1}$ is practically inert. (This is the case even if, as an application of the conduct rules to the pitch, the player's judgment is correct.) Of course, these two- strike $_{1}$ and strike $_{2}$ - are not unrelated: when a spectator declares "It's a strike," she is saying not only that the pitch is a strike ${ }_{1}$ but also that it ought to be a strike ${ }_{2}$; and when the umpire calls "Strike!" he is not merely making the pitch a strike $e_{2}$ but also doing so, it is implied, because he has judged it a strike ${ }_{1}$. But they are nevertheless importantly distinct, and what matters for playing the game is not, it turns out, what the conduct rules themselves might actually say (i.e., whether the pitch is a strike ${ }_{1}$ ) but what the umpire says that they say (i.e., whether it is a strike ${ }_{2}$ ), for the latter is what settles the state of play and makes possible relationships of accountability between the players.

Suppose that our baseball game has an umpire and that he has called the pitch a strike, a call Bashir acts on. The claim implicit in Bashir's action is still addressed to Astrid as a demand, but now we see that it is "The pitch is a strike ${ }_{2}$ !" While the authority Bashir is claiming for this demand does not, on his view, come from him, it also does not come from the rules themselves; it comes from the umpire and, in particular, from the fact that the umpire has issued the judgment making the pitch a strike ${ }_{2}$. What Bashir's demand of Astrid presupposes, then, is not that she is accountable for recognizing "The pitch is a strike 2 !" as what the conduct rules themselves say but that she is accountable for recognizing it as what the umpire says that those rules say. Of course, what the umpire says must be accessible to her, but under normal conditions this requirement is easily met. Provided that the umpire has indeed called the pitch a strike, thereby making it a strike ${ }_{2}$ in the state of play, Bashir's demand of Astrid is vindicated as an authoritative demand within the game, one from within the relationship of accountability they stand in as fellow players. In this way, the mechanism of the umpire makes it possible for players in a baseball game to hold one another accountable for choosing only among legitimate moves in their game play. And, unlike other possible mechanisms, it makes it possible for them to do this as equals: because the umpire is not a player, no player is subject to the authority of any other player. 
We will return now to our state-of-nature game, for we can use this distinction between what the conduct rules say the pitch is $\left(\right.$ a strike $\left._{1}\right)$ and what its status is in the state of play (a strike ${ }_{2}$ ) to restate the problem of unilateralism. In acting within the game, those judgments a player acts on are judgments of the state of play. In the case of Bashir and Astrid, then, they are judgments that the pitch is a strike $e_{2}$ or a ball ${ }_{2}$. But because responsible disagreement about what the conduct rules say about the pitch is possible, it cannot be what the conduct rules say about the pitch — that it is a strike $e_{1}$-that makes the pitch a strike ${ }_{2}$, for then this status will not be accessible to players. And so when Bashir plays their game according to his judgment that the conduct rules say the pitch is a strike, a judgment others can responsibly disagree with, he cannot help but claim that he is what gives the pitch the accessible status their game requires- that is, that what he says the conduct rules say about the pitch makes the pitch a strike $e_{2}$ in the state of play while what Astrid says they say is merely the judgment that the pitch is a ball ${ }_{1}$. In this way, in acting within the game, the judgment Bashir acts on is not the (correct) judgment that the pitch is a strike ${ }_{1}$ but rather the judgment that it has the status of a strike 2 . And so while Enoch's Objection is right that Bashir acts on his judgment here because it is, as he thinks, correct and not because it is his, it is precisely in thinking that this judgment— that the pitch is a strike $e_{2}$-is correct that he claims unilateral authority over the status of the pitch in their game and so over Astrid as a fellow player.

\section{DISAGREEMENT ABOUT RIGHT}

The task now is to argue that this defense of the problem of unilateralism against Enoch's Objection is available not just for state-of-nature versions of certain multiplayer games but also for a state of nature about right. We must show two things. First, we must show that right puts persons in a situation relevantly analogous to that in which players are put by these games. We must show, in other words, that it is as if right places persons in a "game" of equal freedom with those with whom they "cannot avoid interacting," a game whose rules-the rules of right—give them the first right of self-governance (RSG1). By showing this, we will establish that as a game of equal freedom, right must be structured so that persons stand in relationships of accountability with one another about the conduct rules of right. Second, we must show that when it comes to applying these rules of right in particular situations, responsible disagreement between "players" is possible, for this will mean that they will not stand in relationships of accountability in a state-of-nature game of equal freedom in which they also have the second right to self-governance (RSG2). By showing this, we will establish 
that what is required for persons to make valid claims of right of one another is some authoritative mechanism for resolving disputes arising from responsible disagreement such that the various "moves" have one status (i.e., they count as right or not) that those persons are accountable, absent a valid excuse, for recognizing as governing them all.

The result is that a state of nature about right will face the problem of unilateralism defended in the previous section. When a person in a state of nature acts on her own responsible judgment of right, one that admits of responsible disagreement, she cannot help but claim that she is the mechanism for the authoritative resolution of any disputes arising from such disagreement and, consequently, that her judgment of what the conduct rules of right say decides what counts as right. This assertion of unilateral authority means that she cannot help but deny the equal freedom of others, for she is claiming for herself the RSG2the right to act within the "game" according to her own judgments (rather than deferring to some other's judgments) of which "moves," according to the conduct rules of right, are legitimate in the first place-while denying this same RSG2 to them. What right requires is therefore not just any authoritative mechanism for resolving disputes arising from responsible disagreement about right but rather one that is itself compatible with the equal freedom of persons-it must be that no "player" is subject to the authority of another. This mechanism, on Kant's view, will be law.

\subsection{Right as a "Game" of Equal Freedom}

Kant's account of right begins, plausibly enough, with the claim that persons have an innate right to freedom: "Freedom (independence from being constrained by another's choice), insofar as it can coexist with the freedom of every other in accordance with a universal law, is the only original right belonging to every man by virtue of his humanity."19 As Ripstein explains it, "you are independent if you are the one who decides what ends you will use your means to pursue, as opposed to having someone else decide for you." ${ }^{20}$ The freedom at issue here, then, is that of being one's own master, and so whatever else it may require, it at least requires that you have the RSG1: the right to choose for yourself (rather than deferring to some other's judgments), within the bounds set by the rules of right, what ends to pursue and how to pursue them. In this way, we can understand the rules of right as, in part, giving each of us an equal such RSG1, and so as securing for each of us, as it were, equal space in which we may pursue our own ends in our own way. 
My exercise of my RSG1 will change the circumstances on the ground, and in doing so, it may shape the bounds the rules of right give to your exercise of your RSG1. If I acquire some piece of unowned land, you now can do so only by acquiring it from me; if I sell something to another, whether you might acquire it is determined now not by my price but by that other's; if I instead destroy that thing, you simply cannot acquire it. There is thus a sort of interdependence here-my exercise of freedom in our shared circumstances can expand or contract the set of possibilities the rules of right give you to exercise yours-and so, as in a game, we are governed together by those rules of right. It is as if we are players together in a multiplayer "game" of equal freedom, one structured by the rules of right and played on a field of play we share. ${ }^{21}$ We can thus understand the bounds that right gives to the space we each have to pursue our ends as the state of play within our game of equal freedom: these bounds define the choices (or "moves") that in the circumstances are or are not legitimate for you and for me, and these definitions are the product not only of the rules of right themselves but also of what has happened in the game up to this point, the legitimate moves that have already been played and whose results now shape the field of play for us.

Because persons are governed together by the rules of right as if in a game of equal freedom, the rules not only make persons responsible for choosing only legitimate moves but also make it such that they are accountable to their fellows for doing so, for the moves they choose will change the field of play and their fellows are entitled to those changes being legitimate ones. If what I destroyed was not in fact my property but rather yours, I have violated your right and so am accountable to you for that violation-you have standing to demand to be made whole—for you are entitled to have available to you, when you pursue your ends, the moves that access to this property would have made possible. The claim here, then, is that on a Kantian account, what holds for the games considered above holds also for right: the rules of right constitute a system in which persons each have the RSG1. As a result, this system of right-or this game of equal freedommust be structured such that these persons are accountable to one another for staying within the bounds the rules give that right. And, as we saw with those games, persons will be in these relationships of accountability with one another about the rules of right only if the state of play at any $t$ in their game of equal freedom is accessible to them. If I am to be accountable for destroying your property, it must be the case that the fact that it was yours - and so that destroying it required your consent-was accessible not only to you but also to me.

21 Thomas Pogge notes that the system of right can be conceived of as a game ("Is Kant's Rechtslehre Comprehensive?" 170-71). He calls it "Kant's Rechtslehre game." 
There is, however, one important disanalogy. Unlike with these other games, playing this game of equal freedom with those with whom we "cannot avoid interacting" is not optional. Whenever we act in a world we share with others, we thereby act on a judgment of right: at a minimum, the judgment that our action is permitted by right (or, in other words, that it is a legitimate "move" for us). In acting in such a world, then, we implicitly address a claim of right as a demand to those others, a demand that presupposes that they are accountable for recognizing the claim as authoritative: at a minimum, the claim that they not interfere with our action (or, in other words, that they recognize our "move" as legitimate for us). Whenever we act in such a world, it is as if we simply find ourselves already as players in a game of equal freedom with those others, for the claims of right that we, in acting, cannot help but make of others are demands one addresses within such a game to fellow players about the state of play.

\subsection{Responsible Disagreement about Right}

If we cannot help but play in a game of equal freedom with those with whom we cannot avoid interacting, then we must accept whatever is necessary to make such a game playable, for otherwise we will be unable to make valid claims of right of those others. What Kant's state-of-nature argument reveals is that this game of equal freedom, unlike chess, is not playable if the rules of right give players not only the first right of self-governance (RSG1) but also the second (RSG2). We might attempt a close analogy here with our state-of-nature baseball game. When it comes to many questions of right, two people can each find that, even in normal circumstances, from where they stand, responsible deliberation about what the conduct rules of right say about some situation cannot but lead them to different judgments. Persons inevitably face what John Rawls has called "the burdens of judgment," and so such disagreement about many questions of right is inevitable. ${ }^{22}$ And, just as in baseball, the possibility of this sort of disagreement will undermine persons' ability to make claims of right of each other in a state of nature, for they will not be accountable for recognizing the demands others thereby address to them not merely as what those others demand but as what the rules of right themselves demand of them.

But things are not quite so straightforward, as Kant idealizes those in the state of nature about right: they are "however good and right-loving human beings might be." And, as he explains, he does so in order to show that "it is not experience from which we learn of the maxim of violence in human beings and of their malevolent tendency to attack one another before external legislation endowed with power appears, thus it is not some deed that makes coercion through public

22 For discussion of the burdens of judgment, see Rawls, Political Liberalism, 56-57. 
law necessary." ${ }^{23}$ On Ripstein's reading, this idealization signals that "Kant does not follow Hobbes and Locke in focusing on the empirical defects of the state of nature, such as self-preference and limited knowledge." The defects in the state of nature, he argues, "do not reflect human limitations." ${ }^{24}$ It is not clear, however, that we need read this idealization quite so strongly, as removing any and all human limitations. Being a maximally good and right-loving person does not imply, for instance, that one is also maximally informed or perfectly situated, or that one reasons perfectly. Some human limitations would seem to survive this idealization.

I suggest instead that we should imagine persons who are fully committed to pursuing their ends only in ways permitted by right. Such a thoroughgoing commitment will manifest itself not just in the maxims a person acts on in their interactions with others. For instance, a person thus committed will cultivate within themselves all those "rules of moral salience" that, as Barbara Herman has emphasized, are required for one to deliberate and judge well (here, about questions of right). ${ }^{25}$ In this way, it is not simply that these idealized persons mean well—all and only good intentions are not sufficient for such a thoroughgoing commitment to acting rightly—but rather that they have done everything a person might do to see to it that in their interactions with others, they actually succeed in acting rightly. The point is thus that even these idealized persons in normal, or even reasonably favorable, circumstances will disagree with one another at times about how the rules of right apply in their interactions. Or, to put it another way, the point is that there are hard cases of right—cases for which, if there are determinate answers, those answers are not accessible even to these idealized persons. In these cases, a person may entirely succeed in holding herself responsible for judging correctly-she may do everything that could possibly be asked of her as a human agent exercising judgment—and yet, even if she is suitably placed to judge, fail to judge correctly. On this reading, then, the problems of a state of nature about right (indeterminacy and unilateralism) do arise from certain human limitations - namely, the limitations of our faculty of judgment. That we are subject to these limitations means that for many questions of right in a game of equal freedom - the hard cases — responsible disagreement is possible even between our idealized players.

23 Kant, The Metaphysics of Morals, 6:312.

24 Ripstein, Force and Freedom, 146.

25 As Herman explains, rules of moral salience "structure an agent's perception of his situation so that what he perceives is a world with moral features. They enable him to pick out those elements of his circumstances or of his proposed actions that require moral attention" ("The Practice of Moral Judgment,” 77). 
Of course, hard cases in this sense might simply be cases where, as Ripstein and Sinclair argue, right itself is indeterminate. On this view, the correct answers are indeed not accessible even to these idealized persons, but that is simply because, in these cases, there are not any such answers in the first place. Though I incline toward understanding many of these hard cases as having determinate answers (because if they do, it will not be a mistake to aim at the correct answer when exercising judgment about them), the core claim of the larger argument remains even if we accept this alternate view, for what is responsible for the Kantian problems of indeterminacy and unilateralism in a state of nature about right will still be that for many questions of right, there is not one accessible correct answer. The correct answer may not be accessible because, as this alternate view has it, there is not one in the first place, or there may be one, but because of the limitations of human judgment, it is not accessible to us. Either way, what playing a game of equal freedom together requires is that there be one accessible answer, and so the indeterminacy at issue in the state of nature-the one that gives rise to the problem of unilateralism - is the lack of this one accessible answer to these questions of right. (That right itself is indeterminate would thus be sufficient to generate this indeterminacy, but it is not necessary.)

\subsection{Indeterminacy about Right and Unilateralism}

Consider now a responsible disagreement in this idealized state of nature about right. Carlos claims ownership over some plot of land, while Dana claims ownership over a neighboring one. Unfortunately, their claims overlap: there is one field over which they both claim exclusive ownership. While they agree that Carlos's attempted acquisition of that previously unowned field came first, they disagree about whether it was legitimate (and so successful). Carlos thinks the answer is yes (he laid down clear boundary markers and did some preliminary preparation of the field for planting), while Dana thinks the answer is no (while Carlos worked other portions of his plot intensively, there were no clear indications that this field had been worked on). Their disagreement thus concerns the status of the field in the state of play: Carlos judges that he owns it and so both that Dana has an obligation not to trespass on it and that he has the right to use coercion to keep her off of it; Dana makes the opposite judgment. Suppose that the principles of acquisition declare Carlos's acquisition legitimate and so a success. But also suppose that this question-"According to the principles of acquisition, was it legitimate?"-is a hard case and that both Carlos and Dana have deliberated responsibly. What we have, then, is a case of responsible disagreement about a question of right.

Carlos and Dana cannot simply agree to disagree here about who owns this 
field, at least not if their claims of ownership are to be valid claims of right marking the boundary between their respective spheres of freedom. The problem, however, is that they are unable to act from a view of what the rules of right say about this field's ownership that they are both accountable for recognizing as the status of the field in the state of play. In the state-of-nature game in which they find themselves, then, the status of the field—who owns it—is indeterminate. So, what this game requires is some mechanism for resolving their dispute about the status of the field, about who counts as the owner in the state of play, one that will be authoritative for them even if they continue to disagree about what the principles of acquisition say. There is thus a distinction in this case between ownership $_{1}$ and ownership 2 , and it is ownership ${ }_{2}$ of the field-who counts as the owner-that governs their interactions. More broadly, it is what counts as right (their rights ${ }_{2}$ and obligations ${ }_{2}$ ) that governs them, while what according to the conduct rules is right (their rights ${ }_{1}$ and obligations $s_{1}$ ) is practically inert. Within a game of equal freedom, then, the claims of right that persons address to one another as demands are claims of rights ${ }_{2}$ and obligations $s_{2}$, not of rights and obligations $s_{1}$, for they are claims about what the other is accountable for recognizing as authoritative limits on their pursuit of their ends. In this way, the problem for a state of nature about right, even our idealized one, is that it may be indeterminate what these rights $s_{2}$ and obligations $s_{2}$ are, even if it is not indeterminate what the rights ${ }_{1}$ and obligations ${ }_{1}$ are.

Were Carlos to act on his judgment here, moving to force Dana off of the field, the judgment at issue would not be the (correct) judgment that he owns the field but rather the judgment that he owns 2 it. And so, it is true that Carlos's reason for action here would not be "that I believe that Dana is obligated ${ }_{2}$ not to trespass on my land" but rather simply "that Dana is obligated 2 not to trespass on my land." Enoch's Objection is thus correct that on Carlos's view, what justifies his acting on this judgment is that the judgment is, as he believes, correct and not that it is his. The problem cannot be that Carlos treats as special the fact that

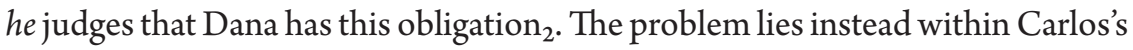
judgment itself. For this judgment to be, as he believes, correct-for the state of play to have it that he owns 2 the field and so that Dana has this obligation ${ }_{2}$ not to trespass - it will need to be the case that his responsible judgment of what the principles of acquisition say here makes it the case that he owns 2 the field while Dana's responsible judgment of what they say here is merely that she owns the field. It is precisely in taking his judgment that he owns ${ }_{2}$ the field to be correct, and so as what governs their interactions concerning this field, that Carlos implicitly claims unilateral authority over the state of play in this part of their 
game of equal freedom and, in that way, over Dana as a fellow player. Enoch's Objection thus fails.

\title{
4. CONCLUSION
}

If our idealized Carlos and Dana are to be able to address valid claims of right to one another, their "game" of equal freedom must have some authoritative mechanism that makes determinate in a way accessible to them what counts as right in it. And since innate equality requires that no particular player's judgment of right decides what counts as right in their game-otherwise we run into the problem of unilateralism - what is required is some other agent whose judgment decides what counts as right for them and who is not a player in the game. This agent is what Kant calls "the omnilateral will": it is empowered to make determinate in a way accessible to them all everyone's rights and obligations within the gametheir rights ${ }_{2}$ and obligations $s_{2}$ - such that players can hold one another accountable for recognizing them as authoritative over their exercise of their RSG1 in their game play; and, crucially, it is not empowered to do anything else. ${ }^{26}$ The basis of the law's claim of authority over citizens is that it is this omnilateral will-a will that by giving laws to everyone solves the problems of indeterminacy and unilateralism that citizens would face were they entirely self-governing, and, in so doing, makes it possible for citizens to stand as equals in relationships of accountability with one another about right. ${ }^{27}$

\author{
University of Delaware \\ dkoltons@udel.edu
}

\section{REFERENCES}

Darwall, Stephen. "Law and the Second-Person Standpoint." In Morality, Authority, and Law: Essays in Second-Personal Ethics I, 168-78. Oxford: Oxford University Press, 2013.

Enoch, David. "Against Public Reason." In Oxford Studies in Political Philosophy,

26 For a more complete account, see Ripstein, Force and Freedom, 190-98.

27 For very helpful comments, objections, and discussion, I am grateful to Seth Shabo, Kaila Draper, Rochelle Duford, and two anonymous reviewers. I also thank audiences at Amherst College, the Eighth Multilateral Kant Colloquium (Catania, Italy), and the University of Delaware to whom I presented earlier versions of some of the ideas contained in this paper. 
vol. 1, edited by David Sobel, Peter Vallentyne, and Steven Wall, 112-42. Oxford: Oxford University Press, 2015.

. "The Disorder of Public Reason." Ethics 124, no. 1 (October 2013): 14176.

. "Not Just a Truthometer: Taking Oneself Seriously (but Not Too Seriously) in Cases of Peer Disagreement." Mind 119, no. 476 (October 2010): 953-97.

. Taking Morality Seriously: A Defense of Robust Realism. Oxford: Oxford University Press, 2011.

Gaus, Gerald. The Order of Public Reason: A Theory of Freedom and Morality in a Diverse and Bounded World. Cambridge: Cambridge University Press, 2011.

Herman, Barbara. "The Practice of Moral Judgment." In The Practice of Moral Judgment, 73-93. Cambridge, MA: Harvard University Press, 1993.

Kant, Immanuel. The Metaphysics of Morals. In Practical Philosophy, translated and edited by Mary J. Gregor, 363-603. Cambridge: Cambridge University Press, 1996.

Pogge, Thomas W. "Is Kant's Rechtslehre Comprehensive?" Southern Journal of Philosophy 36, Spindel Supplement (Spring 1998): 161-87.

Rawls, John. Political Liberalism. New York: Columbia University Press, 1993.

Raz, Joseph. "Disagreement in Politics." American Journal of Jurisprudence 43, no. 1 (1998): 25-52.

Ripstein, Arthur. Force and Freedom: Kant's Legal and Political Philosophy. Cambridge, MA: Harvard University Press, 2009.

Sinclair, Thomas. "The Power of Public Positions: Official Roles in Kantian Legitimacy." In Oxford Studies in Political Philosophy, vol. 4, edited by David Sobel, Peter Vallentyne, and Steven Wall, 28-52. Oxford: Oxford University Press, 2018. 